\title{
Unravelling Urban-Rural Health Disparities in England
}

\author{
Rebecca Allan $^{1}$, Paul Williamson ${ }^{1}$ and Hill Kulu ${ }^{2}$
}

Address:

${ }^{1}$ Centre for Spatial Demographics Research, School of Environmental Sciences, University of Liverpool, Roxby Building, Liverpool L69 7ZT, United Kingdom E-mail: R.L.Allan@ liverpool.ac.uk

${ }^{2}$ Population and Health Research Group, School of Geography and Sustainable Development, University of St Andrews, Irvine Building, St Andrews KY16 9AL, United Kingdom 


\section{Unravelling Urban-Rural Health Disparities in England}

\section{Abstract}

Previous research shows significant health and mortality variations by residential context. Numerous studies report better health and lower mortality among rural populations in comparison to urban residents, whereas other research shows the opposite, with poor health and high mortality in rural areas. This study investigates health variations in England by residential contexts and the causes of such differences. Further, it examines the sensitivity of results to different rural-urban classifications. Applying logistic regression models to individual-level data from the $2001 \mathrm{UK}$ census we demonstrate significant health variation by residential context. A clear urban-rural positive health gradient is apparent, with levels of ill health increasing parallel to levels of urbanisation. Briefly, people living in rural areas have better health than those living in cities and other urban contexts. However, the capital city (London) provides an exception to the gradient, with its inhabitants having better health than anticipated. Once we control for individual socio-demographic characteristics, including occupational status and educational level, the urban-rural health variations are reduced, but significant differences still persist. Most notably, Outer London residents have health expectations similar to those residing in the most rural locations. Clearly, our results support the existence of a positive urban-rural health gradient, with the exception of a protective 'capital city' effect. These findings persist regardless of the precise urban-rural classification used. Finally we show that, having accounted for composition and the rural-urban context, there still remains a North-South divide in health outcomes.

Keywords: health, rural, urban, population census, logistic regression, England 


\section{Introduction}

Research shows that health and mortality vary considerably by residential context. Previous studies in the UK demonstrate poorer health and higher mortality in the North and West, compared to the South and East (Hacking, Muller and Buchan, 2011). The results regarding urban-rural variation, a further dimension of residential context, are less conclusive. Historical studies of England support the notion of the urban penalty; in the late 19th century mortality levels were significantly higher in urban compared to rural settlements (Wood, 2004). Numerous empirical studies indicate the continuation of such a trend, with illness and mortality levels steadily increasing with levels of urbanisation (Chilvers, 1978, DEFRA,2016, Kyte and Wells 2010). In contrast, an alternative stream of research has argued that the rural idyll is progressively becoming a myth, as rural communities come to face issues impinging upon their health (Lankila, et al, 2012). The hypothesis of a U-shaped health continuum has also been proposed, with rural areas and large cities experiencing relatively poor health outcomes, compared to suburban and semi-rural areas which lie in the middle (Barnett, Roderick, Martin and Diamond, 2001).

The reasons for health and mortality variation across the rural-urban continuum are unclear. Some researchers attribute spatial variation to contextual factors, emphasising the significance of an individual's immediate living environment (Wrigley, 2002; Mungall, 2005; Stafford, Chandolam and Marmot, 2007; Maas, et al, 2009; Ruckerl, Schneider and Breitner, 2011). Other researchers emphasise the critical role of compositional factors, proposing that health and mortality vary between locations, as different people inhabit different residential contexts (Sloggett and Joshi, 1994). This paper investigates health variations in England by residential context, with a focus upon urban-rural health differences. The objectives are to determine the relationship between an individual's health and residential context, and to investigate the sociodemographic and economic relationships with urban-rural health variations. Logistic regression models are applied to individual-level data from the 2001 UK census to determine the level of urban-rural health variation, with and without adjusting for individual demographic and socio-economic characteristics. This study extends previous research in the following ways. First, we use large scale individual-level data, allowing for the precise measurement of the relationship between an individual's health and place of residence. Second, we apply multivariate analysis to determine the extent to which individual socio-economic characteristics explain urban-rural health variation and the extent to which other potential contextual factors play a role. Third, our analysis moves beyond the simple 
urban-rural dichotomy still dominant in the literature, and distinguishes between multiple residential contexts along the rural-urban continuum. Fourth, given that there is no universally accepted definition of urban and rural, we test the robustness of our findings to different urban-rural classifications.

\section{Previous research on urban-rural health variation}

Urban-rural positive heath gradient

Historical studies of England support the notion of an urban penalty, with urban areas characterised by poor health in comparison to rural areas. Numerous empirical studies indicate the continuation of urban-rural differences (Wood, 2004; Riva, Curtis and Norman, 2011; DEFRA, 2016). Chilvers (1978) suggested that mortality steadily increases with levels of urbanisation, creating a positive urban-rural health gradient. Charlton (1996) found that for all age groups, people living in rural local authority districts enjoyed the lowest rates of allcause mortality. Kyte and Wells (2010) demonstrated that overall life expectancy was consistently higher in rural compared to urban locations. Further, DEFRA (2016) found that males and females in rural England on average lived respectively two and one-and-a-half years longer than those in urban areas. However, this rural advantage is postulated to vary between population subgroups. O'Rilley et al (2007), for example, observed that the protective effect of rurality fails to extend into older ages, adding that mortality tends to converge at older age groups. Further, gender is also perceived to have a mediating effect upon the health advantage. Previous studies have argued that residential contexts are highly associated with female health, whilst males tend to be influenced by socioeconomic factors to a much greater extent (Kavanagh, Bentley, Turrell, Broom and Subramanian 2006; Stafford Cummins, Macintyre, Ellaway, and Marmot, 2005).

Many studies assume that the rural health advantage is a consequence of contextual differences (Ecob and Jones, 1998), postulating that the advantage is upheld once socioeconomic and demographic factors have been considered. For instance, Riva, Curtis, Gauvin and Fogg (2009) using a UK national sample found that one-fifth of rural residents reported poor health, whereas the figure was one-fourth in urban areas, independent of socioeconomic characteristic. Senior, Williams and Higgs (2000) suggested that one of the foremost factors resulting in mortality and health differentials between rural and urban locations is that individuals residing within the latter tend to be much more deprived. It is well established that deprivation has a strong detrimental relationship with health. 
Furthermore, within the UK the vast majority of measures utilised to consider disadvantage demonstrate that urban areas are commonly more deprived (Davey Smith, Whitley, Dorling and Gunnell, 2001).

Consequently, research suggests that once social class is controlled for, the tendency towards better rural health may disappear. For example, Gartner, Farewell, Roach, and Dunston, (2011) showed that after controlling for area deprivation utilising the Index of Multiple Deprivation (IMD), rural-urban mortality differences reduced substantially.

Similar arguments have been advanced relating to the compositional role of demographic factors. For example, rural residents are more likely to be married, and less likely to be divorced or widowed (Gautier, Svarer and Teulings, 2009), the latter being associated with excess mortality (Waite, 1995; Liu, 2009; Sbarra, Law and Portley, 2011). Excess mortality may also be associated with urban concentration of particular ethnic groups, although research shows that immigrants have better health and lower mortality than natives (Wallace and Kulu 2014).

If rural populations have better health and lower mortality once demographic and socioeconomic characteristics have been controlled for, what then are the contextual factors that account for urban-rural health differences? Maas, Verheij, Groenewegen, de Vries and Spreeuwenberg (2006) argue that the availability of green space is an important factor in explaining the rural-urban health variations. There is growing evidence that natural environments have independent salutogenic effects, as they are both healthier environments to live in and promote improved health related behaviour (Coutts, Chapin, Horner and Taylor, 2013; Maas et al, 2009; Bowler, Buyung-Ali, Knight and Pullin, 2010). Research suggests that exposure to green-space enhances physical activity, and that activity in such settings has superior physiological benefits (Pretty, Peacock, Sellens and Grin, 2005). Furthermore, according to restoration theory the natural environment is said to possess inherent curative qualities, encouraging restoration from attention fatigue (Bowler et al, 2010). Contact with green space also provides protection from the biological effects of stress, reducing diseases of the circulatory system (Mitchell and Popham, 2008).

Another contextual factor is the uneven distribution of crime. The risk of becoming a victim of any household crime is higher in urban compared to rural areas (Higgins, Robb, and Britton, 2010). Higher levels of neighbourhood crime have been associated with a range of negative health consequences, including all-cause mortality as well as health related behaviours (Lorenc et al, 2012). Research suggests that crime acts as a barrier to healthpromoting physical activities. It leads to avoidance behaviours, as urban individuals place 
restrictions on outdoor activities, with elevated risks of cardiovascular disease and poorer physical functioning (Stafford et al., 2007).

Pollution may also play a role. Epidemiological studies have identified a spectrum of adverse health consequences due to exposure, with those located closer to the source, such as urban traffic pollution, faring worst (Ruckerl et al, 2011). Studies have revealed that there is a clear increase in cardiovascular and cardiopulmonary mortality associated with pollutant particulates (Laden, Schwartz, Speizer and Dockery, 2006). Jenke et al (2009) also observed positive associations with circulatory diseases such as acute myocardial infractions, stroke, and coronary heart disease. This complements other research suggesting a clear adversarial association between pollution, lung functioning and respiratory system diseases (Pope and Dockery, 2006).

\section{U-shaped health continuum}

Many researchers have warned against the uncritical acceptance of the positive urbanrural health gradient, as the 'rural idyll' is increasingly being recognised as a myth (Watkins and Jacoby 2007, Kyte and Wells, 2010). Bentham (1984) found a tendency for more remote rural areas to experience higher than expected mortality rates, whilst rural areas bordering main towns had lower than anticipated mortality. In light of such findings Barnett et al. (2001) proposed the theory of a U-shaped association between mortality and population density. The most densely populated locations and the most sparsely populated experience relatively poor health outcomes compared to their counterparts which fall within suburban and semi-rural areas (Verheij, Maas, and Groenewegen, 2008). Jordan, Roderick, Martin, and Barnett's (2004) study of South West England provides supporting evidence, concluding that levels of limiting long-term illness (LLTI) display upwards trends in more remote areas, particularly for the working-age population.

The capital city of London - an exception?

London can also be used to question the validity of the urban-rural positive heath gradient and the notion of a U-shaped association. London is the most populated urban zone within the UK, thus it would be expected to experience the poorest health and the highest mortality levels. According to Riva et al. (2009) this is not the case, with residents of London being less likely to report their health status as fair or poor, in comparison to residents of other cities. Moreover, Norman, Boyle, Exeter, Feng and Popham (2011) suggested that people within London are healthier than would be anticipated given their deprivation levels: 
an outcome Whynes (2009) characterised as the "London effect". The precise reasons for this are unclear. It is believed that London benefits from being situated within the southeast, the wealthiest and healthiest region within the UK. Further, the health selection processes is thought to exert a positive influence. London experiences the highest levels of population growth through internal and international migration. Thus the low mortality experience is thought to be a consequence of the healthy migrant effect, concentrating healthier individuals within the capital (Boyle and Norman, 2010). On the other hand Martin, Brigham, Roderick, Barnett and Diamond (2000) note the pro-urban bias of most area-based deprivation indicators, emphasising the need to revisit this question using individual-level data.

\section{Urban-rural negative health gradient}

Studies on health in London and sparsely populated areas have led some researchers to conclude that the relationship between health and level of urbanisation is positive rather than negative. Lankila et al, (2012) suggested that the share of individuals with poor health tends to increase with decreasing population densities. They observed that mortality rates and poor self-reported health tended to be elevated within the rural context, persisting once sociodemographic factors have been controlled. Smith, Humphreys and Wilson (2008) suggested that rural disadvantage will aggravate the effects of socioeconomic disadvantage, leading to poorer health outcomes than would be expected from deprivation levels. Numerous reasons have been proposed to explain poor health in rural areas.

In the UK, health service centralisation has occurred at an increasing pace (Powell, 1995; Mungall, 2005), leading to the demise of rural health services. Studies have demonstrated that the utilisation of services is inversely related to the distance a patient lives from facilities (Gulliford and Morgan, 2013). As a result, residents will take up services less frequently, leading to adverse health outcomes (Farmer et al, 2006). Haynes and Bentham (1982) showed that consultation rates were substantially higher in urban areas than rural locations for those with a LLTI. The lowest consultation rates were observed in those distant rural areas without health facilities. Such a disadvantage is not felt uniformly, as private transport within rural areas varies, with the elderly and lower classes less likely to possess a car (Jordan, Roderick, and Martin, 2004).

There is consistent evidence that geographical variations in mortality and morbidity mirror variations in food consumption patterns, reflecting local accessibility of healthy foods (Wrigley, 2002). Research shows that the majority have a good knowledge of what constitutes a healthy diet, but that for rural dwellers location conspires against its 
implementation (Liese, Weis, Pluto, Smith and Lawson, 2007). As the power of the multiple has grown, so the market has become made up of fewer and larger urban based retailers (Furey, 2001), leading to inequitable shopping provision. Rural residents, unable to access large multiples, are forced to shop in small independent stores instead (Dawson, et al, 2008). A study conducted by Liese et al, (2007) discovered that the availability of healthy food was substantially higher in supermarkets in comparison to independent stores. Hence, Wang, Williams, Rush, Crook, Forouhi, and Simmons, (2010) found that healthy food was more readily available in urban than in rural environments (Wang et al, 2010). There is also a price penalty with healthy produce costing approximately one-third more in rural environments (Shae 2014). This situation is exacerbated for those living in remote locations, as due to store monopoly retailers are able to charge extortionate prices (Bell, Mora, Hagan, Rubin, and Karpyn, 2013). Consequently, it is argued, healthy food options are no longer affordable to isolated rural residents (Lee et al, 2007).

\section{Methodological issues of previous research}

The vast majority of studies investigating rural-urban health variations and the influence of contextual and compositional factors use ecological data and area-based deprivation/socio-economic measures (such as that of the Townsend Index). Numerous studies investigating measurements of rural deprivation have questioned the validity of the frequently used area-based indices. Such traditional measures are thought to be biased towards the urban community (Levin and Leyland, 2006), leading many researchers to conclude that the use of such indices will lead to severe misrepresentation of deprivation within rural areas (Kyte and Wells, 2010). Further, the analysis of relationships between variables using ecological data may over- or under-estimate the strength of the relationships between various individual characteristics, or even show relationships that do not exist if individual-level data were analysed. This is because, for example, health status is directly affected by personal employment status; and only very indirectly, if at all, by the employment status of others. In contrast the health benefits of a rural environment will accrue to all living within it.

A second challenge is that there is no universally accepted definition of what constitutes rural (Gartner et al, 2011). Over the past two decades the problem of defining rurality has received a great deal of attention within the rural studies literature. In spite of this, according to Higgs (1999) there is little chance of reaching a consensus definition. As a consequence, most academics take a pragmatic approach, utilising measures best suited to 
their own research needs (Martin et al, 2000), ranging from an emphasis on population density through functional labour market areas to the nature of local service provision, land use and built form. By 2007 it was estimated that approximately 30 different definitions were in use across the UK (Scott, Gilbert and Gelan 2007; Pateman 2011). Because of these methodological issues/constraints over the exact definition of 'rural', any observed ruralurban health variations could simply be a data artefact - a consequence of the methods used to define rural areas (Higgs 1999).

\section{Research questions}

Based on previous research, we expect to find significant health differences by residential context. We also expect health variation by residential context to decline once we control for individual characteristics. What remains unclear is, first, whether we will observe a positive or negative urban-rural health gradient; second, to what extent residential variations in health are explained by compositional factors. We also expect results to be sensitive to the area classification utilised. What is uncertain is how and to what extent the urban-rural health gradient will alter. Finally, we expect much of the spatial variability in health outcomes to be accounted for by urban-rural area type and local population composition. Having done so, what remains unclear is the extent to which any wider regional health effects will still persist.

\section{Data and methods}

\section{Data}

The study uses a sample of anonymised records (SARs) of the 2001 UK census; this is a 5\% sample of census microdata, with a total of 2.96 million individual records. The study population is restricted to the 1.79 million individuals aged 20 and older. The data allow the cross-classification of individuals by ten-year age groups, place of residence, occupational status and limiting long-term illness, enabling the examination of the relationship between health, social class and rural-urban residence at the individual level.

We use limiting long-term illness as a proxy for individual health status; information which comes from the 2001 census question, 'Do you have any long term illness, health problem or disability which limits your daily activities or the work that you can do?' This dichotomous variable relies upon self-assessment, thus it does not reflect any direct medical diagnosis, challenging its objectiveness (Bentham, Eimermann, Haynes, Lovett, and Brainard, 1995). Having said this, previous research provides support for this approach, 
reinforcing the validity of utilising self-assessed measures of health (Rees, Wohland and Norman, 2009). For example, studies have discovered that results of LLTI correlate well with data regarding GP consultations, along with outpatient hospital visits (Boyle, Norman, and Rees, 2002). Moreover, self-rated health has been revealed to be a powerful predictor of subsequent mortality, suggesting that individuals are good judges of their own health (Drever, Doran, and Whitehead, 2004).

Control variables used in this study are 'Age', 'Sex', 'Occupational status', 'Highest level of Qualification', 'Ethnicity' and 'Marital status'. 'Ethnicity' was recoded into six categories consisting of: White (White British, White Irish, White Other), Black (African and Caribbean), South Asian (Indian, Bangladeshi and Pakistani), Other Asian (Chinese and Other Asian), Mixed and Other. 'Highest level of Qualification' also comprises six categories: 'Level 4/5' (First degree, Higher degree), 'Level 3' (A levels) 'Level 2' (5+ GCSEs) 'Level 1' (1-4 GCSEs), 'No Qualification' and 'Other Qualification/Level Unknown'. 'Occupational status' was recoded into five categories: Upper class (managerial and professional occupations); Middle class (intermediate occupations); Lower class (routine and manual occupations); Never worked / Long term unemployed; and finally Not applicable. Those individuals aged 20 to 64 lacking a recorded occupational status were distributed evenly across age groups for both males and females. The same cannot be said for individuals aged less than 20 or over 64 . Thus this variable is representative of the working age sample, but not of the 'non-working age' $(<20 ; 65+)$ sample. This is taken account of in the analyses that follow (Table 1).

To explore the impact of rural-urban classification upon the observed rural-urban health gradient, this paper compares six alternative classifications of the Local Authority Districts (LAD) within which individuals reside. LADs are administrative spatial units with populations in the range of 2,153 (Isles of Scilly) to 977,087 (Birmingham) with a median of 112,797 individuals.

The first rural-urban classification (RUC) considered is the ONS 2001 RUC, consisting of a six fold core grouping made up of: Major Urban, Large Urban, Other Urban, Significant Rural, Rural 50 and finally Rural 80. This classification categorizes LAD's according to settlement size and built form, with the main emphasis upon identifying the type of settlement along with the wider geographical context in which such settlements are placed (Kyte, and Wells, 2010).

Whynes (2009) and Norman et al (2011) both suggest that the capital city might provide a protective health effect. For this reason our second classification again utilises the 
ONS RUC, but separates out London from the other 'Major Urban' locations; whilst the third classification further subdivides London into Inner and Outer London. In both cases London LADs are categorized using the ONS London Borough classification.

The fourth classification relies upon the idea of 'functional regions' (c.f. Halas Klapka, Tonev, and Bednar, 2015), utilising LAD population size, density and commuting flows. Functional regions were created by merging LADs linked by commuting flows of at least $15 \%$ of the employed population in the origin LAD in 2001, provided the destination LAD had a population of at least 200,000 . The resulting functional regions were then classified according to their population density (residents per $\mathrm{km}^{2}$ ) as follows: London, Cities 3000+, Cities 2000+, Counties 1000+, Counties 500+, Counties 250+, Counties 100+ and finally Counties $<100$ residents per $\mathrm{km}^{2}$. A similar classification, combining settlement hierarchy (based on LAD population size and density) with functional regions has previously been used in the study of urban-rural fertility variation to control for the effect of selective residential moves (Kulu and Washbrook 2014).

The final two classifications considered only population density, using alternative sixfold classifications (equal intervals and sextiles), as there is no logical breakpoint for any measure of population density, meaning that any categorisation is necessarily artificial (Higgs, 1999). A sixfold categorisation was used to match the six categories in the original ONS 2001 RUC.

\section{Methods}

We use a logistic regression model to study health by residential context. The model is formalised as follows:

$$
\ln \frac{p\left(Y_{i}=1\right)}{1-p\left(Y_{i}=1\right)}=\alpha+\sum_{k} \beta_{k} x_{i k}
$$

Where $p\left(Y_{i}=1\right)$ is the probability of suffering from a limiting long-term illness for individual $i, \alpha$ is a constant, $x_{i k}$ is the value of variable $k$ for individual $i$, with $k$ variables. The results are presented in the form of odds ratios, i.e. odds of having an LLTI for a particular group relative to the reference group. The reference categories for each variable are as follows: age (youngest), ethnicity (white), sex (male), marital status (single), occupational status (managerial and professional occupations), highest level of qualification (Level 4/5) and residence (rural 80). In our model urban-rural residence is treated as a fixed effect which fully captures the clustering of individuals within urban-rural classes. 
Model 1 controls for age and sex (all ages). Model 2 divides the age range into two smaller groups, 20-64 ('working age') and 65+ ('post working age'). Occupational status is recorded reliably only for persons aged 20-64. For the working-age population only, Model 3 controls for occupational status to determine if health variations decline once we control for social class. Model 4 additionally controls for level of qualification. Finally model 5 further controls for ethnicity and marital status.

As previously mentioned there is no universally accepted definition of what constitutes rural, thus researchers have suggested that any observed health variation would potentially be a reflection of the classification used. In an attempt to select the best classification possible and to test the robustness of results, each of the five logistic regression models outlined above were fitted utilising the six alternative RUCs under consideration.

One stream of research has shown that residential environment has a stronger association with self-reported health among women (Kavanagh et al, 2006 Stafford et al 2005). Alternatively, apparent gender differences may largely be due to the inability of occupational status to capture the effect of socioeconomic status on mortality among women. To explore the interaction of sex with these factors, we initially conducted our modelling process separately for males and females. However, the results that emerged were broadly similar, with a comparable rural-urban health pattern identified for each sex. The only noteworthy exception was for model 3 , which found that male health was influenced by social class to a much greater extent than female health. For simplicity's sake, therefore, this paper presents results from models in which sex is included only as a main effect.

\section{Analysis}

\section{Model Fits}

For each rural-urban classification Table 2 displays the fit of Model 1, and the improvement over successive models as additional covariates are added. The results for Model 2 show that the best performing RUC is an extended ONS RUC, which distinguishes inner and outer London. Notably, separating the capital into inner and outer London improves the model fit considerably compared to the original ONS RUC.

As might be expected, model fit improves for all classifications as additional covariates are added. However, the largest improvement is observed when NSSEC is controlled for. Having taking account of RUC and the compositional variables in the model, controlling for regional location (North-South) still leads to model improvement. 
Given these results, the remainder of this paper focuses on Models utilising the extended ONS RUC, justified both by the observed superiority of model fit, and by theoretical considerations. The ONS RUC was devised to reflect critiques of existing classifications and is recommended by DEFRA (2005) as the 'de facto' standard for the analysis of rural-urban differences; whilst others have also noted the possible existence of a 'capital city effect' (Whynes, 2009; Norman et al., 2011).

\section{Results: Rural-urban health differentials}

Figure 1 demonstrates that levels of limiting long-term illness vary by both age and place of residence. As anticipated the proportion of individuals possessing an LLTI increases with age (Marshall and Norman 2013). For younger age groups (20-39), levels of illness by residential location appear to be largely similar (within a 3\% range), chiefly explained by small absolute differences between the residential groups and reduced levels of LLTI in younger cohorts. From age 40 onwards a rural-urban health gradient is more clearly detectable. Individuals residing within major urban areas consistently possess the highest levels of LLTI, whilst the lowest levels are experienced by those living in the most rural locations. Levels of ill health increase with levels of urbanisation, with the exception of London, which experiences reduced levels of LLTI, most notably in outer London where levels of LLTI are similar to those in 'significant rural' locations.

As Table 3 shows, the observed rural-urban health gradient persists regardless of whether we study all adults (Model 1); working age adults (Model 2a) or pensionable age adults (Model 2b). For example, those individuals aged 20-64 residing in Major Urban areas are 54\% more likely to develop an LLTI in comparison to those residing in the most rural locations. Furthermore, the odds are also relatively high for those residing in Large Urban areas (37\%) and Other Urban areas (30\%) (Table 3, Model 2a). One main exception to the gradient exists: London. Rather than displaying the highest relative levels of LLTI, levels in the capital are actually lower than expected. Whilst working-age adults in Inner London are still $41 \%$ more likely to develop an LLTI than those residing in rural locations, they are 13 percentage points less likely than those residing in major urban locations. Outer London residents fare even better, with observed health risks almost as low as for those in rural locations. Overall we conclude that the urban-rural health gradient is more or less constant with age within the working age population (20-64), whilst that the gradient reduces, but persists, into old age. Norman and Boyle (2014) report similar evidence of convergence in the 
ill health experience at older ages when examining health differences between areas with differing levels of deprivation.

Model 3 controls for NSSEC, whilst Model 4 further controls for education, and Model 5 for ethnicity along with marital status. Once these additional covariates are incorporated, health variations across the rural-urban continuum reduce substantially, most notably once social class is accounted for. Nonetheless, noteworthy differences persist. Those residing in urban locations remain significantly more likely to develop an LLTI than those living in the most rural locations, with Major, Large and Other urban residents 25\%, $20 \%$ and $17 \%$ more likely to develop an LLTI (Table 3, Model 5). The already observed London exception also remains. After controlling for the additional covariates, residents in Outer London are as likely to have an LLTI as those in the most rural areas (Rural 80) and notably healthier than residents in all other parts of the rural-urban continuum, whilst Inner London residents are healthier than all non-London urbanites.

The influence of covariates corresponds to expectations. Health is worst among men, unemployed and never-worked individuals, those from lower occupational statuses and those with low educational qualifications (Table 3, Model 5). The idea that males experience poorer health in comparison to females is far from new; higher male mortality rates have been explained by a variety of possible biological and behavioural causes (Kalben, 2000; Kruger, 2004). Asians and Other ethnic groups have better health than White British, whereas Indian, Black and those with mixed ethnicity seem to have poorer health. Previous research has demonstrated low mortality for all immigrant groups (Wallace and Kulu 2014). Whether observed differences are due to poor health among the descendants of immigrants or because of a weaker association between health and mortality among immigrants and ethnic minorities is a topic for future research. Finally, married individuals have better health than single and separated, which is also expected (Table 3, Models 5).

\section{Gradient sensitivity - Test for robustness}

To test the robustness of the results presented above, logistic regression was performed utilising alternative rural-urban classifications. Figure 2 demonstrates the sensitivity of results based upon the classification implemented. The overall finding is that for all classifications a rural-urban health gradient may be observed and that these effects persist, in attenuated form, once all individual-level covariates have been included in the model. Clearly, levels of ill health increase parallel to increasing urbanisation. For those classifications separating out London, a 'capital city effect' may be observed. As the rural 
urban health gradient is observed for all classifications, this sensitivity analysis shows that our findings are robust and not simply a consequence of the method used to define rural areas.

\section{Spatial pattern of model residuals}

Figure 3(a) displays the spatial distribution of residuals from Model 5 using the ONS RUC inner and outer London adjustment, highlighting the locations in which ill health is either over or under predicted by the model. The RUC is utilised to understand if the predictive power of the model is improved once regional influences are controlled (the NorthSouth divide). It is clear that the majority of locations within the South of England, with the exception of the far South West and central London, are either adequately or over predicted, i.e. health is better than the model forecasts. In contrast districts in the North (particularly the most Northern) are under predicted, along with those districts in the tip of the South West, with individuals experiencing health worse than predicted. This finding persists regardless of the actual rural urban classification used.

Given that a clear spatial patterning is observable (spatial pattern of either over or under prediction of LLTI) in the model residuals, an attempt has been made to account for these using a simple North-South dichotomy. The division was set by aggregating the nine government office regions of England into the five northernmost and four southernmost locations. The dividing line was set between the Wash and the Severn Estuary, a line commonly adopted within existing literature. For example, it is said to represent the division in life expectancy amongst the southern and northern regions (Hacking et al, 2011). Other regional classifications were also tested including the South-East versus rest of England and even region of residence. These were found at best to only marginally improve model fit. Interaction effects between RUC and the North-South divide were also investigated. No interactions of substantive interest were found.

As Figure 3(b) shows, once the North-South divide is taken into account, the spatial pattern of model residuals alters. Model over-prediction in the South becomes restricted to a narrower ring around London, whilst model under-prediction spreads out across the most rural locations (the South West and northern East Anglia). In the North, model underprediction shrinks to pockets focussed mainly on the major urban conurbations, such as Merseyside and Tyneside.

Controlling for the North-South divide marginally improves the predictive power of the model, but some spatial patterning of the model residuals remains. Evidently, spatial 
health variations are not simply a matter of rural-urban and compositional differences, but of broader regional differences too, particularly between the South and the North.

\section{Conclusion and discussion}

This study has examined health variation by residential context in England. Our analysis found a positive urban-rural health gradient, with individuals residing in urban locations consistently possessing the worst self-reported health, and those in rural areas the best. However, once London was separated out from other urban areas, residents of the capital were found to possess better than anticipated health. This was particularly the case for those residing in outer London, who were found to have health expectations similar to those in the most rural locations. The observed urban-rural health gradient was substantially reduced, but persisted once we controlled for individual characteristics, particularly occupational status and education. Thus our results lend partial support to those who argue for a positive urbanrural health gradient, with the exception of a protective 'capital city' effect.

A significant portion of the initial urban-rural health gradient was explained by the different socioeconomic composition of residential contexts; the share of unemployed and never-worked individuals was the largest in large cities and the smallest in rural contexts. Interestingly, potential differences in marital status, e.g. higher divorce rates in urban areas combined with higher marriage rates in rural areas, and the presence of increased ethnic minorities within the urban context, explained very little health variation by residential setting, suggesting that the results are robust to various individual characteristics. What, then, are the factors that account for better health in rural areas and deteriorating health with increasing urbanicity? We suggest a number of possible influences related to the living environment such as levels of exposure to green space, pollution, crime and proximity of living.

This leaves unexplained the health advantage of London - the 'capital city effect'. Our analysis demonstrated that self-rated health amongst residents of the capital was better than expected, once we adjusted our models to control for individual socio-economic characteristics. Based on our discussion of contextual influence, it would be expected that the individuals living in London would possess the worst health amongst all areas in England, which, as the study showed, was not the case. We suggest that this anomaly may possibly be a consequence of selective migration (cf. Andersson and Drefahl 2016). First, the healthiest individuals move to London to study and work. Second, those with poorer health may migrate from London to other residential contexts, potentially to other urban areas. Such a 
double selection would leave London with a (internal) migrant population with good health. The role of selective migrations is thus an important topic for further investigation, which this study, based on the cross-sectional census data, was not able to address (Norman et al, 2011). Alternatively, it might be that the compositional factors used in our study fail to adequately capture between-area heterogeneity in wages and living conditions with, for example, professionals in London earning more than their counterparts elsewhere.

Within the capital, we discovered that those residing in inner London possessed substantially poorer relative health in comparison to those living within outer districts of the capital. Possible reasons for the inner London disadvantage are many. First, according to Haynes (2016) much of the housing within the inner city is in disrepair, with residential, transport and workplace overcrowding common in comparison to the outer capital, facilitating the transfer of infectious diseases. Further, the inner city population is thought to be more transient, thus immunisation and preventative health programmes are more difficult to implement, and are taken up less frequently (Bardsley and Morgan 1996). Finally, again migration is thought to play a part, with inner city residents relocating to outer London following improved employment opportunities, with these individuals tending to be healthier than those left behind (cf. Tunstall, Pearce, Mitchell and Shortt, 2015).

The validity of previous studies of the urban-rural health gradient has been questioned due to the lack of a universal definition of 'urban' and 'rural'. Hence it has been argued that observed rural-urban health variations are a data artefact, reflecting the classification used. Our investigation refutes such critique, as the observed rural-urban health gradient has been found to be impervious to the classification utilised.

Further, this investigation provides an insight into urban-rural effects in the light of the North-South divide, a further dimension of residential context which has been largely overlooked in existing research. Controlling for this divide, alongside other sociodemographic factors, the spatial pattern of model residuals alters and model fit improves (although the urban-rural gradient persists). Hence it is evident that health variations are not only an urban-rural issue. All rural (and urban) locations are not equal. Rather, there are regional effects to take into account besides the urban-rural influences investigated here.

The fact that a spatial pattern to the model residuals remains even after controlling for rural-urban classification, socioeconomic and demographic factors, and position within the North-South divide, suggests that there must be factors that the model has failed to capture. We suggest possible explanations similar to those we have offered for the observed 'capital city effect': health selective migration and unobserved between-area heterogeneity in wages 
and living conditions, some of which we suggest will be explained by regional economic structures. Future research should look to investigate such issues.

This study was conducted with data collected from England, so it is important to consider if the observed results can be generalised for different contexts. We would expect to find comparable results in many European countries due to the similarities in characteristics of the rural and urban environments. However, for some other industrialised countries, for example Australia and Canada, the differences across rural populations may be larger than in the UK, as some rural areas are extremely remote. Further, in contrast to Western Europe, rural areas in developing nations will often experience much more poverty in comparison to urban locations (Gartner et al, 2011). It is for these reasons that results would be expected to vary between countries. Along with different locations it is also important to consider different scales, and whether the same results would be produced at different geographical levels. We would expect the positive urban-rural gradient to hold, regardless of the geographical level investigated. However, it is important that future research examines ruralurban health variations at the lower level.

The data utilised within this study were collected in 2001, as it was the latest data available which encompassed all the required information. A critical reader may question the applicability of the findings 15 years later. Based on our study and previous research we believe that the basic differences in health across the various locations have persisted. However, future research should investigate whether the variations have grown or reduced over time. Future research should also focus on the role that selective migrations (or longdistance moves) may play in health variation by residential context; on the role of unobserved heterogeneity of income/wealth within occupational and educational qualification groupings; and on possible gender differences. Migration is, however, selective of certain demographic and socioeconomic characteristics which have been controlled within this study, thus we may have already partially accounted for such migration effects. Moreover, it also remains to be seen whether mortality levels vary by residential context in ways similar to those observed in this paper for morbidity. 


\section{Acknowledgements}

The authors are grateful to anonymous referees for valuable comments and suggestion on a previous version of this article. We are further grateful to the ONS and the UK Data Service for providing access to the Census 2001 Small Area Microdata (SAM) (project 96107) Rebecca Allan's research was supported by the Economic and Social Research Council (PhD project: "Residential Context, Health and Mortality: The Effect of Context, Composition or Selective Migrations?”). 


\section{References}

1. Andersson, G., Drefahl, S. (2016). Long-Distance Migration and Mortality in Sweden: Testing the Salmon Bias and Healthy Migrant Hypotheses. Population, Space and Place. DOI: 10.1002/psp.2032. (Published online.)

2. Bardsley, M., Morgan, D. (1997). Deprivation and Health in London: An Overview of Health Variations in the Capital. The London Journal, 22(2),142-159. DOI: 10.1179/ldn.1997.22.2.142

3. Barnett, S., Roderick, P., Martin, D., Diamond, I. (2001). A Multi-Level Analysis of the Effects of Rurality and Social Deprivation on Premature Limiting Long Term Illness. Journal of Epidemiol Community Health, 55 (1), 44-51. DOI:10.1136/jech.55.1.44

4. Bentham, G. (1984). Mortality Rates in the More Rural Areas of England and Wales. Area, $16(3), 219-226$.

5. Bentham, G., Eimermann, J., Haynes, R., Lovett, A., Brainard, J. (1995). Limiting Long Term Illness and its Associations with Mortality and Indicators of Social Deprivation. Journal of Epidemiol Community Health, 49 (2), 57-64. DOI: 10.1136/jech.49.Suppl_2.S57

6. Bowler, D,. Buyung-Ali, L., Knight, T., Pullin, A. (2010). A Systematic Review of Evidence for the Added Benefits to Health of Exposure to Natural Environments. BMC Public Health, 10, 456-466. DOI: 10.1186/1471-2458-10-456

7. Boyle, P., Norman, P. (2010). Migration and Health. In Brown, T. McLafferty, S. Moon,G. (2010) The Companion to Health and Medical Geography (pp356-375). West Sussex: Wiley Blackwell

8. Boyle, P., Norman, P., Rees, P. (2002). Does Migration Exaggerate the Relationship between Deprivation and Limiting Long-Term Illness? A Scottish Analysis. Social Science and Medicine, 55 (1), 21-31. DOI: 10.1016/S0277-9536(01)00217-9.

9. Charlton, J. (1996). Which areas are the healthiest? Population Trends, 83, 17-24

10. Chilvers, C. (1978). Regional mortality 1969-73. Population Trends, 11, 16-20

11. Coutts, C., Chapin, T., Horner, M., Taylor, C. (2013). County Level Effects of Green Space Access on Physical Activity. Journal of Physical Activity and Health, 10 (2),232240. DOI: 10.1123/jpah.10.2.232

12. Dawson, J., Marshell, D., Taylor, M., Cummins, S., Sparks, L., Anderson, A. (2008). Accessing Healthy Foods: Availability and Price of a Healthy Food Basket in Scotland. Journal of Marketing Management, 24 (9), 893-913. DOI: 10.1362/026725708X381957. 
13. Defra (2005) Classification of Local Authority Districts and Unitary Authorities in England: A Technical Guide. London: Rural Evidence Research Centre.

14. DEFRA (2016) Rural Health Available at: https://www.gov.uk/government/collections/rural-living Accessed 12/12/14

15. Drever, F., Doran, T., Whitehead, M. (2004). Exploring the Relation between Class, Gender, and Self-rated General Health using the New Socioeconomic Classification. A Study using Data from the 2001 Census. Journal of Epidemiol Community Health, 58 (7), 590-596. DOI:10.1136/jech.2003.013383.

16. Ecob, R.. Jones, K. (1998). Mortality Variations in England and Wales between Types of Place: An Analysis of the ONS Longitudinal Study. Social Science and Medicine ,47 (12), 2055-2066. DOI: 10.1016/S0277-9536(98)00310-4

17. Farmer, J., Iversen, L., Campbell, N., Guest, C., Chesson, R., Deans, G., MacDonald, J. (2006). Rural/Urban Differences in Accounts of Patients' Initial Decisions to Consult Primary Care. Health and Place,12 (2),210-221. DOI: 10.1016/j.healthplace.2004.11.007.

18. Furey, S. (2001). An Investigation of the Potential Existence of 'Food deserts' in Rural and Urban areas of Northern Ireland. Agriculture and Human Values, 18 (4), 447-457. DOI: $10.1023 / \mathrm{A}: 1015218502547$

19. Galea, S., Vlahov,D. (2005). Urban health: Evidence, Challenges and Directions. Annual Review Public Health, 26, 34163 .DOI:10.1146/ annurev.publhealth .26.021304.144708

20. Gartner, A., Farewell, D., Roach, P., Dunston, F.(2011). Rural/Urban Mortality Differences in England and Wales and the Effect of Deprivation Adjustment. Social Science and Medicine, 72 (10) ,1685-1964. DOI: 10.1016/j.socscimed.2011.03.017.

21. Gautier, P., Svarer, M., Teulings, C. (2009). Sin City? Why is Divorce Rate Higher in Urban in Urban Areas. Scandinavian Journal of Economics, 111 (3), 439-456. DOI: 10.1111/j.1467-9442.2009.01571.

22. Gulliford, M., Morgan, M. (2013). Access to Health care. Oxon:Routledge

23. Hacking,J., Muller,S., Buchan,I. (2011). Trends in Mortality from 1965 to 2008 across the English North-South Divide: Comparative Observational Study. British Medical Journal, 342, 1-9. DOI:10.1136/bmj.d508.

24. Halas, M., Klapka, P., Tonev, P., Bednar, M. (2015). An alternative definition and use for the constraint function for rule-based methods of functional regionalisation. Environment and Planning A, 47 (5), 1175-1191. doi: 10.1177/0308518X15592306.

25. Haynes, R. (2016). The Geography of Health Services in Britain. Oxon: Routledge 
26. Haynes, R., Bentham, C. (1982). The Effects of Accessibility on General Practitioner Consultations, Out-Patients Attendances and In-Patient Admissions in Norfolk England. Social Science Medicine, 16 (5), 561-569. DOI:10.1016/0277-9536(82)90309-4

27. Haynes, R., Gale, S. (1999). Mortality Long-term Illness and Deprivation in Rural and Metropolitan Wards of England and Wales. Health and Place, 5 (4), 301-312. DOI:10.1016/S1353-8292(99)00020-9.

28. Higgs,G. (1999). Investigating Trends in Rural Health Outcomes: A Research Agenda. Geoforum, 30 (3), 201-22. DOI: 10.1016/S0016-7185(99)00021-4.

29. Higgins, N., Robb, P., Britton, A. (2010). Geographic Patterns of Crime. In: Home Office (2010) Crime in England and Wales 2009/1: Findings from the British Crime Survey and Police Recorded Crime (165-194). London: Home office

30. Jenke, J., Propper, C., and Henderson, J. (2009). Do Current Levels of Air Pollution Kill. The Impact of Air Pollution as Population Mortality in England and Wales. Health Economics, 18 (9), 1031-1055. DOI: 10.1002/hec.1475.

31. Jordan, H., Roderick, P., Martin, D. (2004). The Index of Multiple Deprivation 2000 and Accessibility Effects on Health. Journal of Epidemiol Community Health, 58, 250-257. DOI:10.1136/jech.2003.013011

32. Jordan, H., Roderick, P., Martin, D., Barnett,S. (2004). Distance, rurality and the need for care: access to health services in South West England. International Journal of Health Geographics, 3 (1), 21-30. DOI: 10.1186/1476-072X-3-21

33. Kalben, B. (2000). Why men die younger: Causes of mortality differences by sex. North American Actuarial Journal, 4 (4), 83-111. DOI: 10.1080 /10920277. 2000. 10595939

34. Kavanagh, A., Bentley, R., Turrell, G., Broom, D., Subramanian, S. (2006). Does Gender Modify Associations between Self-rated Health and the Social and Economic Characteristics of Local Environments? Journal of Epidemiol Community Health, 60 (4), 490-495. DOI:10.1136/jech.2005.043562 .

35. Kruger,D. (2004). Sexual Selection and the Male: Female Mortality Ratio. Evolutionary Psychology, 2 (1), 66-85. DOI: 10.1177/147470490400200112.

36. Kulu, H, Washbrook, E. (2014). Residential context, migration and fertility in a modern urban society. Advances in Life Course Research, 21,168-182. DOI: 10.1016/j.alcr.2014.01.001

37. Kyte,L., Wells,C. (2010). Variations in Life Expectancy Between Rural and Urban Areas of England 2001-2007. Health Statistics Quarterly, 46, 25-50. 
38. Laden, F., Schwartz, J., Speizer, F., Dockery, D. (2006). Reduction in Fine Particulate Air Pollution and Mortality. American Journal of Respiratory and Critical Care Medicine, 173(6), 667-672. DOI: 10.1164/rccm.200503-443OC.

39. Lankila ,T., Najha, S., Rautio, A., Nordstrom, T., Koiranen, M., Taanila, A., Rusanen, J. (2012). Self-Reported Health in Urban- Rural Continuum: A Grid Based Analysis of Northern Finland Birth Cohort 1966. International Journal of Public health, 57 (3), 525 533. DOI: 10.1007/s00038-011-0286-0.

40. Lee, A., Darcy, A., Leonard, D., Groos, A., Stubbs, C., Lowson, S., Dunn, S., Coyne, T., Riley, M. (2007). Food Availability, Cost disparity and Improvement in Relation to Accessibility and Remoteness in Queensland. Australian and New Zeeland Journal of Public Health, 26 (3), 266-272. DOI:10.1111/j.1467-842X.2002.tb0016.

41. Levin, K., Leyland, A. (2006). A comparison of health inequalities in urban and rural Scotland. Social Science and Medicine, 62 (6), 1457-1464. DOI: 10.1016/ j.socscimed.2005.08.045

42. Liese, A., Weis, K., Pluto, D., Smith, E., Lawson,A. (2007). Food Store Types, Availability, and Cost of Foods in a Rural Environment. Journal of the American Dietetic Accusation, 107 (11), 1916-1923. DOI: 10.1016/j.jada.2007.08.012.

43. Liu, H. (2009). Till death do us part: marital status and U.S. mortality trends, 1986-2000. Journal of Marriage and Family, 71(5), 1158-1173. DOI: 10.1111/j.17413737.2009.00661.

44. Lorenc, T., Clayton, S., Neary, D., Whitehead, M., Petticrew, M., Thomson, H., Cummins, S., Sonowden, A., Renton, A. (2012). Crime, Fear of Crime, Environment, and Mental Health and Wellbeing: Mapping Review of Theories and Causal Pathways. Health and Place, 18 (4), 757-765. DOI:10.1016/j.healthplace.2012.04.001.

45. Maas, J., Verheij, R., Groenewegen, P., de Vries, S., Spreeuwenberg, P. (2006). Green Space, Urbanity, and Health: How Strong is the Relation? Journal of Epidemiol Community Health, 60 (7), 587- 592. DOI :10.1136/jech.2005.043125

46. Maas, J., Verheij, R., de Vries, S., Spreeuwenberg, D., Schellevis, P., Groenewegen,G. (2009). Morbidity is Related to a Green Living Environment. Journal of Epidemiol Health, 63 (12), 967-973. DOI:10.1136/jech.2008.079038.

47. Marshall, A., Norman, P. (2013). Geographies of the impact of retirement on health in the United Kingdom. Health and Place 30, 1-12 
48. Martin, D., Brigham, P., Roderick, P., Barnett, S., Diamond, I. (2000). The (Miss) Representation of Rural Deprivation. Environment and Planning A, 32(4), 735-751. DOI: $10.1068 / \mathrm{a} 32130$

49. Mitchell, R., Popham, F. (2008). Effect of Exposure to Natural Environment on Health Inequalities: An Observational Population Study. The Lancet, 372 (9650), 1655-1660. DOI: $10.1016 / \mathrm{S} 0140-6736(08) 61689$.

50. Mungall, I. (2005). Trends Towards Centralisation of Hospital Services and its Effects on Access to Care for Rural and Remote Rural Counties in the UK. Rural and Remote Health, 5 (2), 390-398.

51. Norman, P., Boyle. P., Exeter, D., Feng, Z., Popham, F. (2011). Rising Premature Mortality in the UK's Persistently Deprived Areas: Only a Scottish Phenomenon? Social Science and Medicine, 73, 1575-1584. DOI: 10.1016/j.socscimed.2011.09.034

52. Pateman, T.(2011). Rural and Urban Areas: Comparing Lives Using Rural/Urban Classifications. Regional Trends, 43 (1), 11-86. DOI: 10.1057/rt.2011.2

53. Pope, C., Dockery, D. (2006). Health Effects of Fine Particulate Air Pollution: Lines that Connect. Journal of Air Waste Management Association, 56 (6), 709-742. DOI: 10.1080/10473289.2006.10464485.

54. Powell, M. (1995). On the Outside Looking in: Medical Geography, Medical Geographers, and Access to Health Care. Health and Place, 1 (1), 41-50. DOI:10.1016/1353-8292(95)00005-7.

55. Pretty, J., Peacock, J., Sellens, M., Griffin, M. (2005). The Mental and Physical Health Outcomes of Green Exercise. International Journal of Environmental Health Research, 15 (5), 319-37. DOI: 10.1080/09603120500155963.

56. Rees,P., Wohland,P., Norman,P. (2009). The Estimation of Mortality for Ethnic Groups at Local Scale within the United Kingdom. Social Science and Medicine, 69 (11), 15921607. DOI: 10.1016/j.socscimed.2009.08.015.

57. Riva, M., Curtis, S., Norman , P. (2011). Residential Mobility within England and Urban-Rural Inequalities in Mortality. Social Science and Medicine, 73 (12), 1698-1706. DOI: 10.1016/j.socscimed.2011.09.030.

58. Riva, M., Curtis, S., Gauvin, L., Fogg, J. (2009). Unravelling the Extent of the Inequalities in Health Across Urban and Rural Areas: Evidence from a National Sample in England. Social Science and Medicine, 68 (4), 654-663. DOI:10.1016/j.socscimed.2008.11.024. 
59. Ruckerl, R., Schneider, A., Breitner, S. (2011). Health Effects of Particulate Air Pollution. A Review of Epidemiological Evidence. Inhalation Toxicology, 23 (10), 555592. DOI:10.3109/08958378.2011.593587.

60. Sbarra, D., Law,R., Portley, R. (2011). Divorce and Death: A Meta-Analysis and Research Agenda for Clinical, Social, and Health Psychology. Perspectives on Psychological Science, 6(5), 454-474. DOI: 10.1177/1745691611414724.

61. Scott, A., Gilbert, A., Gelan, A. (2007). The Urban-Rural Divide: Myth or Reality SERG Policy Brief. Aberdeen: The Macaulay Institute.

62. Senior, M., Williams, H., Higgs, G. (2000). Urban-rural mortality differentials: controlling for material deprivation. Social Science and Medicine, 51 (2), 289-305. DOI: 10.1016/S0277-9536(99)00454-2

63. Shaw, H. (2014). The Consuming Geography of Food: Diet Food Deserts and Obesity. Oxon: Routledge.

64. Sloggett, A., Joshi, H. (1994). Higher Mortality in Deprived Areas: Community or Personal Disadvantage? British Medical Journal, 309 (6967), 1470-1474. DOI:10.1136/bmj.309.6967.1470.

65. Smith, K., Humphreys, J., Wilson, M. (2008). Addressing the Health Disadvantage of Rural Populations: How does Epidemiological Evidence Inform Rural Health Policies and Research. The Australian Journal of Rural Health, 16 (2), 56-66. DOI: 10.1111/j.14401584.2008.00953.

66. Davey Smith, G., Whitley, E., Dorling, D., Gunnell, D. (2001). Area Based Measures of Social and Economic Circumstances: Cause Specific Mortality Patterns Depend on the Choice of Index. British Medical Journal, 55 (2), 149-50. DOI: 10.1136/ jech. 55.2.149

67. Smith, M., Sunil, T., Salazar, C., Rafique, S., Ory. M. (2013). Disparities of Food Availability and Affordability within Convenience Stores in Bexar County, Texas. Journal of Environmental and Public Health, 2013, 1-7. DOI:10.1155/2013/782756.

68. Stafford, M.. Cummins, S.. Macintyre, S.. Ellaway, A.. Marmot, M. (2005). Gender Differences in the Associations between Health and Neighbourhood Environment. Social Science Medicine, 60 (8), 1681-1692. DOI: 10.1016/j.socscimed.2004.08.028

69. Stafford, M., Chandolam, T., Marmot, M. (2007). Associations between Fear of Crime and Mental Health and Physical Functioning. American Journal of Public Health, 97 (11), 2076-2081. DOI: 10.2105/AJPH.2006.097154.

70. Bell, J., Mora, G., Hagan, E., Rubin, V., Karpyn, A. (2013). Access to Healthy Foods and why it Matters. Oakland: Policy Link 
71. Tunstall, H., Pearce, J., Mitchell, R., Shortt, N. (2015). Residential Mobility and the Association between Physical Environment Disadvantage and General and Mental Health. Journal of Public Health, 38 (3), 563-572. DOI: 10.1093/pubmed/fdu058.

72. Verheij, R., Maas, J., Groenewegen, P. (2008). Urban- Rural Health Differences and the Availability of Green Space. European Urban and Regional Studies, 15 (4), 307-316. DOI: $10.1177 / 0969776408095107$.

73. Waite, L. (1995). Does Marriage Matter. Demography, 32 (4), 483-507. DOI: $10.2307 / 2061670$.

74. Wallace, M., Kulu, H. (2014). Migration and Health in England and Scotland: a Study of Migrant Selectivity and Salmon Bias. Population Space and Place, 20 (8), 694-708. DOI: 10.1002/psp.1804

75. Wang, J., Williams, M., Rush, E., Crook, N., Forouhi, N., Simmons, D.(2010). Mapping the Availability and Accessibility of Healthy Food Rural and Urban New Zealand Te Wai o Rona: Diabetes Prevention Strategy. Public Health Nutrition, 13 (7), 1049-1055. DOI: https://doi.org/10.1017/S1368980009991595.

76. Watkins, F., Jacoby, A. (2007). Is the Rural Idyll Bad for your Health? Stigma and Exclusion in the English Countryside. Health and Place, 13 (4), 851-864. DOI: 10.1016/j.healthplace.2007.02.002.

77. Whynes, D. (2009). Deprivation and Self-reported Health: are there 'Scottish effects' in England and Wales? Journal of Public Health, 31(1),147-153. DOI: 10.1093/pubmed/fdn089.

78. Wood, J. (2004). Rural Health and Health Care: A North West Perspective. Lancaster: North West Public Health Observatory

79. Wrigley, N. (2002). Food Deserts in British Cities Policy Context and Research Priorities. Urban Studies, 39 (11), 2029-2040. DOI: 10.1080/0042098022000011344 
Table 1 Descriptive Statistics of the Sample

\begin{tabular}{|c|c|c|c|c|}
\hline \multirow[b]{2}{*}{ Variable } & \multicolumn{2}{|c|}{ Overall } & \multicolumn{2}{|c|}{ LLTI } \\
\hline & Count & $\%$ & Count & $\%$ \\
\hline \multicolumn{5}{|l|}{ Age } \\
\hline $20-24$ & 114527 & 6.4 & 7535 & 6.6 \\
\hline $25-29$ & 156264 & 8.7 & 10975 & 7.0 \\
\hline $30-39$ & 376327 & 21.0 & 34908 & 9.3 \\
\hline $40-49$ & 325300 & 18.2 & 46143 & 14.2 \\
\hline $50-59$ & 307807 & 17.2 & 70776 & 23.0 \\
\hline $60-64$ & 119013 & 6.7 & 40443 & 34.0 \\
\hline $65-74$ & 204573 & 11.4 & 84063 & 41.1 \\
\hline $75-84$ & 137360 & 7.7 & 78920 & 57.5 \\
\hline $85+$ & 47538 & 2.7 & 36186 & 76.1 \\
\hline \multicolumn{5}{|l|}{ Sex } \\
\hline Male & 855942 & 47.9 & 185570 & 21.7 \\
\hline Female & 932767 & 52.1 & 224379 & 24.1 \\
\hline \multicolumn{5}{|l|}{ Marital Status } \\
\hline Single & 431164 & 24.1 & 64033 & 14.9 \\
\hline Married & 989200 & 55.3 & 20475 & 20.7 \\
\hline Separated & 368345 & 20.6 & 141165 & 38.3 \\
\hline \multicolumn{5}{|l|}{ Ethnicity } \\
\hline White & 1662477 & 92.9 & 386104 & 23.2 \\
\hline Black & 32211 & 1.8 & 6084 & 18.9 \\
\hline Mixed & 14394 & 0.8 & 2490 & 17.3 \\
\hline S Asian & 59063 & 3.3 & 12264 & 20.8 \\
\hline O Asian & 13788 & 0.8 & 2177 & 15.8 \\
\hline Other & 6776 & 0.4 & 830 & 12.2 \\
\hline \multicolumn{5}{|c|}{ Residence ONS RUC } \\
\hline Major Urban & 614670 & 34.4 & 143415 & 23.3 \\
\hline Large Urban & 261935 & 14.6 & 64085 & 24.5 \\
\hline Other Urban & 242581 & 13.6 & 55741 & 23.0 \\
\hline Significant Rural & 237491 & 13.3 & 51333 & 21.6 \\
\hline Rural 50 & 216007 & 12.1 & 48472 & 22.4 \\
\hline Rural 80 & 216025 & 12.1 & 46903 & 21.7 \\
\hline \multicolumn{5}{|c|}{ Residence ONS RUC London Adjustments } \\
\hline Inner London & 90633 & 5.1 & 17935 & 19.8 \\
\hline Outer London & 166363 & 9.3 & 32998 & 19.8 \\
\hline Major Urban & 357674 & 20.0 & 92482 & 25.9 \\
\hline Large Urban & 261935 & 14.6 & 64085 & 24.5 \\
\hline Other Urban & 242581 & 13.6 & 55741 & 23.0 \\
\hline Significant Rural & 237491 & 13.3 & 51333 & 21.6 \\
\hline Rural 50 & 216007 & 12.1 & 48472 & 22.4 \\
\hline Rural 80 & 216025 & 12.1 & 46903 & 21.7 \\
\hline
\end{tabular}




\begin{tabular}{|l|r|r|r|r|}
\hline Managerial and Professional & 479802 & 26.8 & 36337 & 7.6 \\
\hline Intermediate & 284500 & 15.9 & 30043 & 10.6 \\
\hline Routine and Manual & 465390 & 26.0 & 61695 & 13.3 \\
\hline Never Worked/Long Term Unemployed & 60739 & 3.4 & 22112 & 36.4 \\
\hline N/A and Not Defined & 498278 & 27.9 & 259762 & 52.1 \\
\hline Education & & & & \\
\hline Level 4/5 & 337521 & 18.9 & 34584 & 10.2 \\
\hline Level 3 & 108159 & 6.0 & 10992 & 10.2 \\
\hline Level 2 & 284370 & 15.9 & 33536 & 11.8 \\
\hline Level 1 & 270869 & 15.1 & 32855 & 12.1 \\
\hline Other Qualification/ Level Unknown & 120408 & 6.7 & 27121 & 22.5 \\
\hline No Qualification & 482484 & 27.0 & 155755 & 32.3 \\
\hline N/A & 184898 & 10.3 & 115106 & 62.3 \\
\hline Total & $\mathbf{1 7 8 8 7 0 9}$ & $\mathbf{1 0 0 . 0}$ & $\mathbf{4 0 9 9 4 9}$ & $\mathbf{2 2 . 9}$ \\
\hline
\end{tabular}




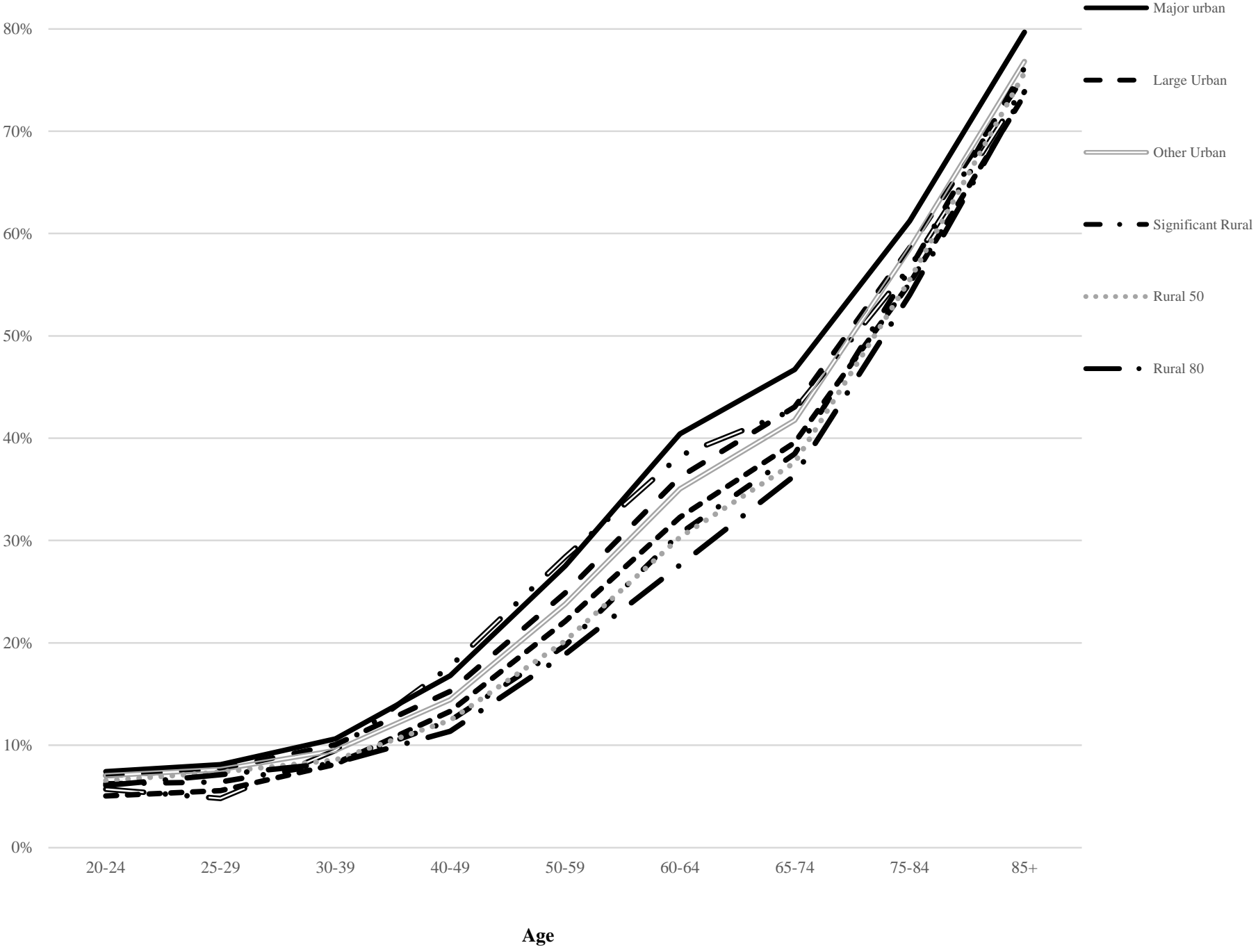

Figure 1 Share of Individuals with Limiting Long-term Illness 
Table 2: Model Fit and Improvement

\begin{tabular}{|c|c|c|c|c|c|c|}
\hline \multirow{2}{*}{ Model } & \multicolumn{6}{|c|}{ Rural-Urban Classification } \\
\hline & ONS RUC & ONS RUC L Sep & $\begin{array}{l}\text { ONS RUC L } \\
\text { inner outer }\end{array}$ & Density Sextiles & $\begin{array}{l}\text { Density Equal } \\
\text { Intervals }\end{array}$ & $\begin{array}{l}\text { Functional } \\
\text { Regions }\end{array}$ \\
\hline \multicolumn{7}{|c|}{ Model Fit (-2 Log Likelihood) } \\
\hline 1. Age and Sex & 1117625.42 & 1117625.42 & 1117625.42 & 1117625.42 & 1117625.42 & 1117625.42 \\
\hline $\begin{array}{l}\text { 2. Age, Sex and } \\
\text { Classification }\end{array}$ & 2887.665 & 3665.012 & 3932.059 & 3474.484 & 1344.827 & 3386.001 \\
\hline $\begin{array}{l}\text { 3. Age, Sex, Classification } \\
\text { and NSSEC }\end{array}$ & 108737.824 & 108403.306 & 108247.187 & 108409.523 & 109542.957 & 108833.108 \\
\hline $\begin{array}{l}\text { 5. Age, Sex, Classification, } \\
\text { NSSEC, Education, Marital } \\
\text { status and Ethnicity }\end{array}$ & 7657.309 & 7771.094 & 7691.692 & 7648.457 & 7739.186 & 8018.594 \\
\hline $\begin{array}{l}\text { 7.Age, Sex, Classification, } \\
\text { NSSEC, Education, Marital } \\
\text { status, Ethnicity and North } \\
\text { South }\end{array}$ & 1464.831 & 1082.661 & 1082.382 & N/A & N/A & N/A \\
\hline
\end{tabular}


Table 3: ONS RUC London Inner and Outer Logistic Regression Results

\begin{tabular}{|c|c|c|c|c|c|c|c|c|c|c|c|c|}
\hline & Model 1 & & Model 2 a & & Model 2 b & & $\begin{array}{l}\text { Model } \\
3\end{array}$ & & $\begin{array}{l}\text { Model } \\
4\end{array}$ & & $\begin{array}{l}\text { Model } \\
5\end{array}$ & \\
\hline & 20-85+ & & $20-64$ & & 65-85+ & & $20-64$ & & $20-64$ & & $20-64$ & \\
\hline \multicolumn{13}{|l|}{ Rural 80} \\
\hline Rural 50 & 1.08 & **** & 1.09 & $* * *$ & 1.06 & $* * *$ & 1.08 & **** & 1.07 & $* * *$ & 1.07 & $* * *$ \\
\hline Significant Rural & 1.08 & **** & 1.07 & *** & 1.10 & $* * *$ & 1.06 & *** & 1.05 & *** & 1.04 & $* * *$ \\
\hline Other Urban & 1.27 & *** & 1.30 & $* * *$ & 1.23 & $* * *$ & 1.23 & $* * *$ & 1.20 & $* * *$ & 1.17 & $* * *$ \\
\hline Large Urban & 1.33 & **** & 1.37 & *** & 1.25 & $* * *$ & 1.27 & **** & 1.23 & **** & 1.20 & $* * *$ \\
\hline Major Urban & 1.51 & **** & 1.54 & $* * *$ & 1.45 & $* * *$ & 1.34 & **** & 1.28 & *** & 1.25 & $* * *$ \\
\hline Outer London & 1.11 & *** & 1.13 & $* * *$ & 1.09 & $* * *$ & 1.05 & $* * *$ & 1.05 & $* * *$ & 1.01 & \\
\hline Inner London & 1.35 & *** & 1.41 & $* * *$ & 1.21 & $* * *$ & 1.22 & **** & 1.23 & *** & 1.12 & *** \\
\hline \multicolumn{13}{|l|}{ Male } \\
\hline Female & .99 & $* *$ & .97 & $* * *$ & 1.02 & $* *$ & .72 & $* * *$ & .73 & $* * *$ & .74 & $* * *$ \\
\hline \multicolumn{13}{|l|}{ Professional/ Higher Managerial } \\
\hline Intermediate Occupations & & & & & & & 1.41 & $* * *$ & 1.23 & $* * *$ & 1.22 & $* * *$ \\
\hline Routine and Manual Occupations & & & & & & & 1.84 & **** & 1.45 & $* * *$ & 1.43 & $* * *$ \\
\hline Never Worked and Long-Term Unemployed & & & & & & & 8.32 & $* * *$ & 6.05 & **** & 5.55 & $* * *$ \\
\hline Not Applicable/Not Defined & & & & & & & 10.17 & $* * *$ & 8.15 & **** & 7.95 & $* * *$ \\
\hline \multicolumn{13}{|l|}{ Level 4/5 } \\
\hline Level & & & & & & & & & 1.11 & *** & 1.11 & *** \\
\hline Level 2 & & & & & & & & & 1.17 & $* * *$ & 1.18 & $* * *$ \\
\hline Level 1 & & & & & & & & & 1.20 & $* * *$ & 1.21 & $* * *$ \\
\hline Other qualification/Level unknown & & & & & & & & & 1.47 & **** & 1.50 & **** \\
\hline No qualification & & & & & & & & & 1.83 & *** & 1.83 & $* * *$ \\
\hline White & & & & & & & & & & & & \\
\hline Black & & & & & & & & & & & 1.00 & \\
\hline Mixed & & & & & & & & & & & 1.17 & *** \\
\hline Indian & & & & & & & & & & & 1.12 & $* * *$ \\
\hline Asian & & & & & & & & & & & .89 & $* * *$ \\
\hline Other & & & & & & & & & & & .70 & $* * *$ \\
\hline Single & & & & & & & & & & & & \\
\hline Married & & & & & & & & & & & .59 & $* * *$ \\
\hline Separated & & & & & & & & & & & .93 & $* * *$ \\
\hline
\end{tabular}

Note: All models are controlled for age; age groups used in the analysis are defined in Table 1. 
Figure 2: Health Variations According to Classification
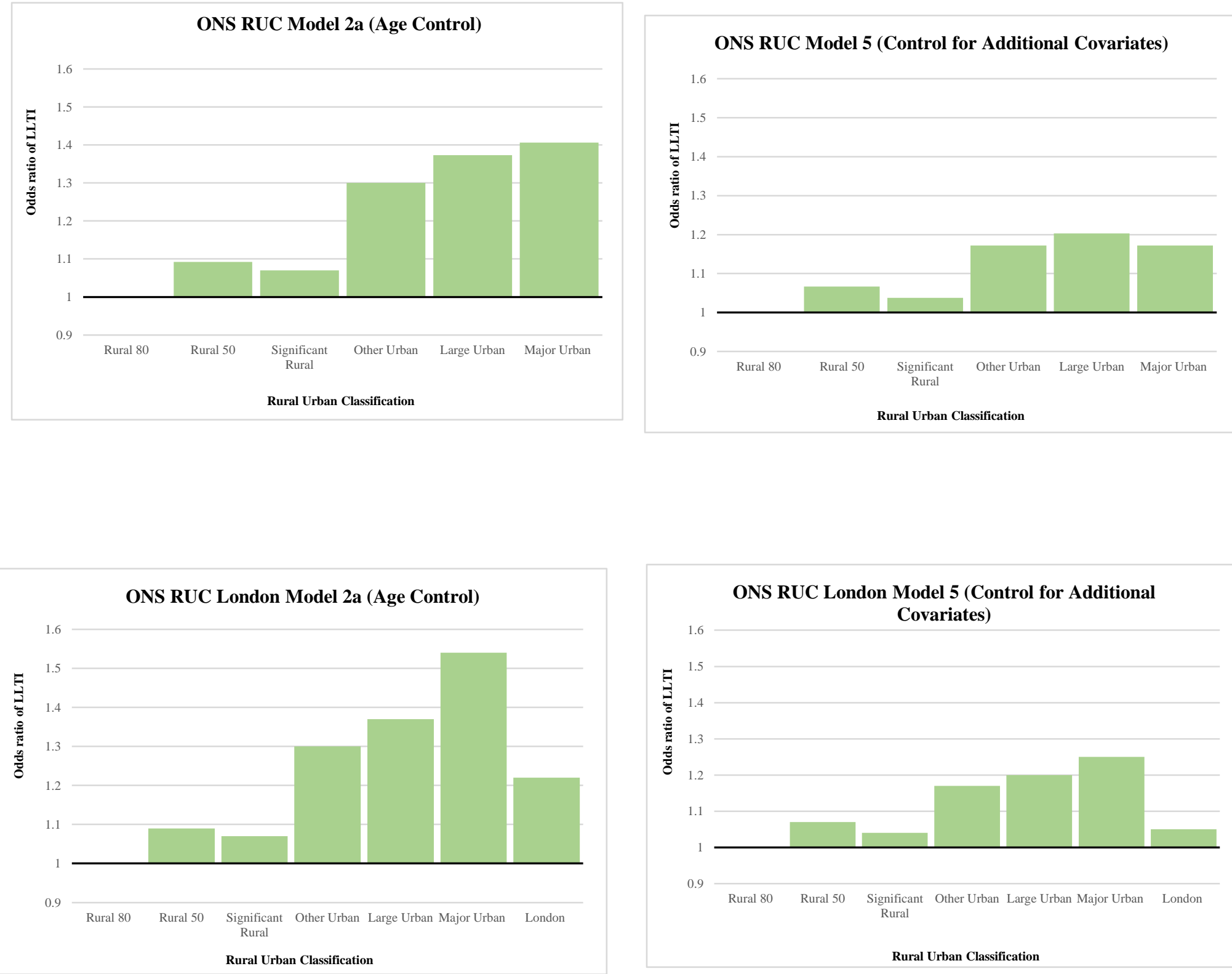

ONS RUC Inner and Outer London Model 2a (Age Control)

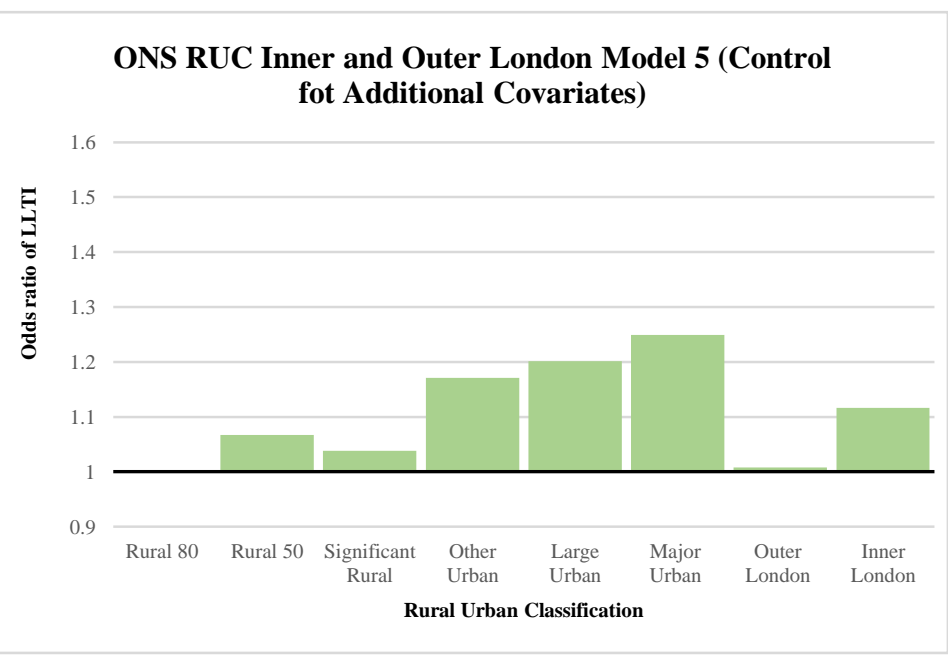




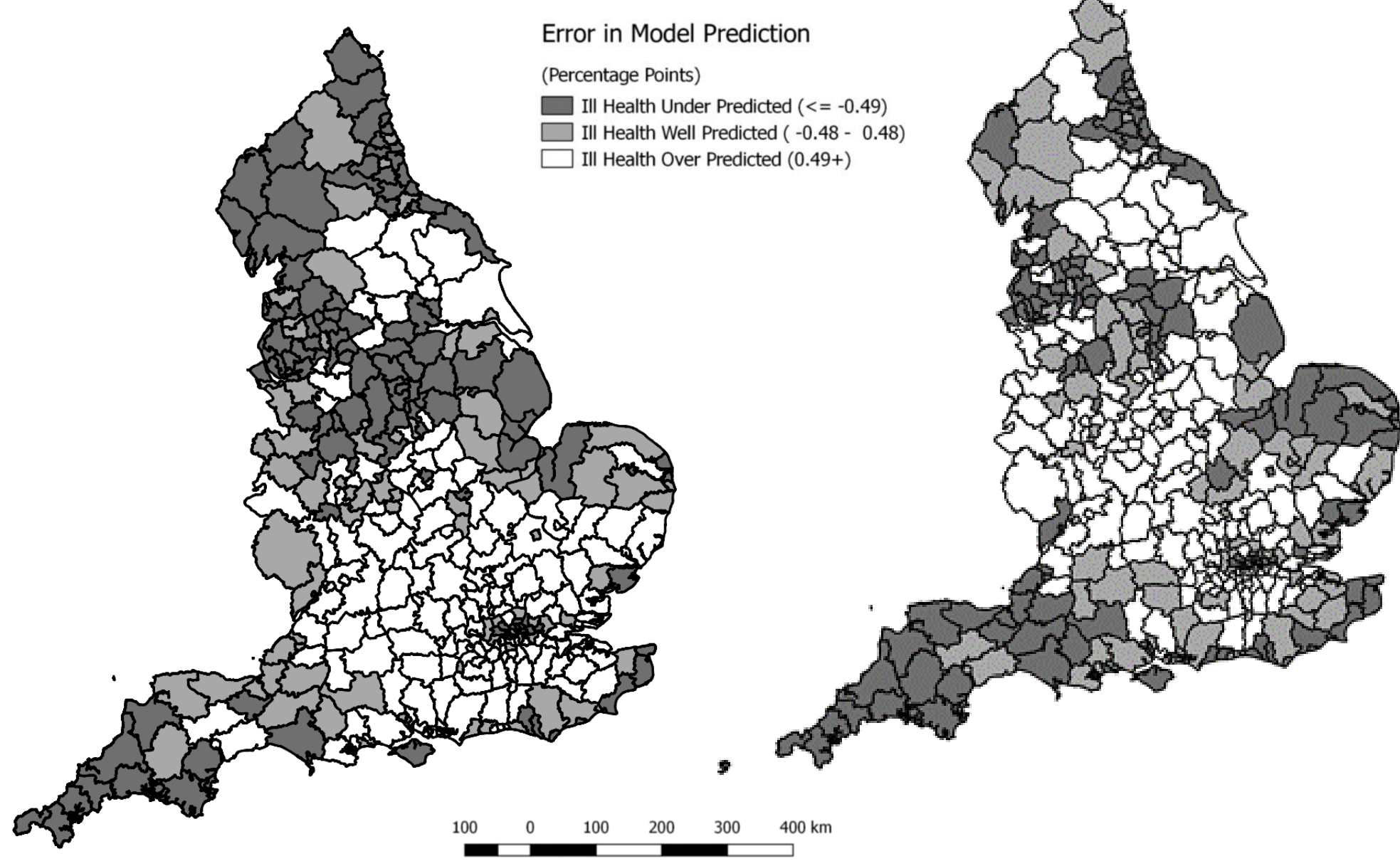

(a)Residuals from Mr (b)Residuals from Model 5 plus

control for North-South divide

Figure 3: Model predictions of \% persons in ill health, controlling for ONS Rural-Urban Classification and Inner/Outer London effects. 